\title{
Population demographics and trade-offs to reproduction of an invasive and noninvasive species of Rubus
}

\author{
Susan C. Lambrecht-McDowell ${ }^{1,3, *}$ \& Steve R. Radosevich ${ }^{2}$ \\ ${ }^{1}$ Environmental Sciences Program, Oregon State University, 321 Richardson Hall, Corvallis, OR 97331, \\ USA; ${ }^{2}$ Department of Forest Science, Oregon State University, Corvallis, OR 97331, USA $;{ }^{3}$ Current \\ address: Department of Biological Sciences, San Jose State University, San Jose, CA 95192-0100, USA; \\ *Author for correspondence (e-mail: slambrec@email.sjsu.edu; fax: +1-408-924-4840)
}

Received 2 January 2004; accepted 18 February 2004

Key words: density, elasticity, exotic, invasion, matrix model, non-native, Rubus

\begin{abstract}
Do trade-offs between growth and reproduction differ between an invasive and noninvasive plant species and how do such trade-offs relate to population demographics? To help address these questions, we compared demographics for an invasive plant species, Rubus discolor, with a noninvasive congener, $R$. ursinus, in several populations of varying density. Removal of floral buds from reproductive canes increased the size of juvenile canes that arose from clonal sprouting in $R$. ursinus, suggesting a trade-off between current reproduction and growth. Removal of floral buds had no effect on growth of $R$. discolor. R. ursinus displayed trade-offs between reproduction (sexual and vegetative) and future growth based on negative correlations between leaf area production and both clonal sprouting and seedling production during the previous year. R. discolor did not exhibit these trade-offs. Both species had high population growth rates in low-density populations, but exhibited little or no growth in high-density populations. A life table response experiment was used to determine the underlying cause for the effect of density on population growth. For R. ursinus, lack of population growth in high-density populations was due primarily to increased mortality of clonally sprouting canes, while for $R$. discolor, it was due to decreased clonal cane production. Elasticity analysis revealed that clonal growth was more important than sexual reproduction for population growth of both species. However, elasticity values for sexual reproduction in $R$. discolor were greater in high- than low-density populations. This suggests an increased reliance on sexual reproduction in populations that had reached stable sizes, which could increase the capacity of $R$. discolor to disperse to new sites. Elasticity analyses were also used to simulate the efficacy of various control strategies for $R$. discolor. Control of this species could be attained by reducing clonal production within existing populations while reducing seed production to limit establishment of new populations.
\end{abstract}

\section{Introduction}

Invasiveness in plant species has been correlated with the ability to reproduce abundantly and grow rapidly. Reproductive traits, such as the capacity for both sexual and vegetative reproduc- tion, an ability to self-fertilize, a lack of seed dormancy, and multi-seeded fruit, have been related to invasiveness because they confer the capacity to rapidly colonize a site, which is the first stage of the invasion process (Baker 1965; Bazzaz 1986; Reichard and Hamilton 1997; Daehler 
1998; Sakai et al. 2001). Fast growth rates reflect rapid acquisition and allocation of resources, which enable a species to swiftly establish a population following colonization. While life-history theory predicts a trade-off between high reproduction and growth rates (Stearns 1992), research examining growth, competitive ability, and reproduction in purple loosestrife (Lythrum salicaria), a noxious wetland invader, suggests that not all invasive plant species are subject to such tradeoffs (Keddy et al. 1994). There is relatively little direct experimental evidence or observational data examining the life-history trade-offs of reproduction in invasive plant species.

The trade-offs between reproduction and growth are due to competition for limited resources within an individual (Stearns 1992). The mechanisms underlying these trade-offs are physiological, where reproductive effort may be expressed as the amount of resources (e.g., carbon) allocated to reproduction at the expense of other functions (Geber 1990; Fox and Stevens 1991; Stearns 1992). The consequences of allocation to reproduction, along with the constraints imposed by resource availability, are expressed at the demographic level and are called the longterm or demographic costs of reproduction (Fox and Stevens 1991; Nicotra 1999). It is at this level that the costs of reproduction may be observed as a decrease of growth or increase of mortality associated with increased reproduction. The balance among these demographic trade-offs of reproduction ultimately determines the population growth rate for a species.

Theory predicts that high allocation of resources to reproduction confers a competitive advantage during site colonization, but that allocation of resources should shift to vegetative growth after colonization to facilitate population establishment (Sakai et al. 2001). Thus, densitydependent shifts in resource allocation between sexual reproduction and vegetative growth may be expected. However, relatively little is known about density effects on population growth rates of invasive plant species or how these effects compare with those found in native species (Parker 2000). Even less is known about the specific life-history factors that contribute to population growth at different densities as an invasion progresses.
Demographic matrix analysis can be used to assess population growth and the factors that contribute to it and may have valuable management applications. For example, they can be used to identify the most important life-history stage or process to the population growth of a species, information which can be used to guide decisions with the objective of sustaining or increasing the population size of rare species (e.g., Charron and Gagnon 1991; Maschinski et al. 1997; Kaye et al. 2001) or to target and decrease the population size of invasive species (e.g., Maxwell et al. 1988; Shea and Kelly 1998; McEvoy and Coombs 1999; Parker 2000). A further application of demographic analyses to invasive plant study is they can provide valuable, but often ignored, insights into the connection between theories of plant invasions and quantitative field data, such as determining whether population growth remains constant throughout the stages of invasion (Parker 2000).

The native, noninvasive $R$. ursinus Cham. and Schlect. (trailing blackberry) and the invasive $R$. discolor Weihe and Nees (also R. procerus; Himalayan blackberry) are members of the same sub-genus (Rubus), share many life-history characteristics, and often grow together in the same sites in the Pacific Northwest United States (PNW). A recent study compared the reproductive effort between these species (McDowell and Turner 2002). Reproduction in the noninvasive species was associated with decreased leaf water status, causing early stomatal closure, and with decreased leaf nitrogen concentration, contributing to lower photosynthetic capacity. However, these physiological costs of reproduction were not observed in the invasive Rubus. The objective of the current study is to examine the implications of these physiological costs at the plant and population scales. We used stage-based demographic models and field experiments and observations to address the following questions: (1) What are the demographic trade-offs between reproduction and growth and how do they differ between an invasive species and a noninvasive congener? (2) How do these trade-offs affect the population demographics of these two species? and 3) How do population demographics influence invasiveness and potential control strategies of $R$. discolor, the invasive species? 


\section{Materials and methods}

\section{Study species}

Rubus ursinus is native to the PNW. Its canes typically grow to about $3 \mathrm{~m}$ in length and produce approximately 25 fruit per cane in a year (McDowell and Turner 2002). R. ursinus is considered noninvasive in its native range, where this study took place. $R$. discolor was first introduced to the PNW from Europe via India for fruit production (Kent 1988) and is considered an invasive plant species outside of its native range because it can grow, reproduce, and proliferate following introduction. Canes of $R$. discolor can grow to $10 \mathrm{~m}$ in length and produce over 700 fruit in a year (McDowell and Turner 2002).

Rubus ursinus and $R$. discolor share several morphological and ecological characteristics. They grow together in open to moderately shady sites at low- (sea-level) to mid- $(\sim 2000 \mathrm{~m})$ elevations in the PNW. Both species are described as biennial/perennial, indicating that roots are perennial while above-ground canes live for two years. However, canes arising from seeds actually develop for three years. Seeds germinate in the winter or early spring and plants remain in a seedling stage for approximately one year. In the following year, canes remain vegetative while nearly all elongation occurs. In the spring of the third season, the canes shed their leaves and develop lateral reproductive shoots. The entire cane senesces following reproduction. Both species have perennial rhizomes (below-ground stems) that can produce and simultaneously support several clonally sprouted canes that emerge and grow as vegetative canes for one year and reproduce in the following year. Therefore, in contrast to the canes that arise from seeds, the canes that arise clonally develop for only two years, but in both cases, the roots may be perennial. An additional form of clonal spread that may occur in both species, as in several other $R u$ bus species, arises when the tip of a cane roots in the soil, forming a new perennial root crown (Heslop-Harrison 1959). As with other species of Rubus, clonal spread from above-ground and below-ground structures may be very important to the population growth of both of these species (Heslop-Harrison 1959; Baret et al. 2003)

\section{Study site}

All research was conducted within the McDonald-Dunn Research Forest near Corvallis, OR $\left(44^{\circ} 40^{\prime} \mathrm{N}, 123^{\circ} 20^{\prime} \mathrm{W}, \sim 350 \mathrm{~m}\right.$ elevation) which receives approximately $300 \mathrm{~cm}$ of rain annually, as measured at a nearby $(\sim 5 \mathrm{~km})$ meteorological station (Oregon Climate Service). In 1999, plots were established around existing populations of each species in a recent clearcut for demographic monitoring. Populations were selected to represent either early population colonization (presumed based on low density of the target species) or established populations (high density of the target species). Therefore, low-density populations for both species were selected to have approximately 6-12 canes each while high-density populations had approximately 45-55 canes each. To control for the same number of individuals per population between the species, plot sizes for $R$. discolor were larger than for $R$. ursinus because $R$. discolor canes are approximately twice as large. Eight high- and low-density $5 \times 5 \mathrm{~m}$ plots were established for $R$. discolor and six high- and low-density $2 \times 2 \mathrm{~m}$ plots were established for $R$. ursinus. Fewer populations were selected for $R$. ursinus because there were fewer populations available of the appropriate densities. In 2001, six additional plots were established around populations of varying densities of each species to be used for an experiment manipulating sexual reproduction. All populations were located within $0.5 \mathrm{~km}$ of each other in a large clearcut, with similar levels of irradiance and potential access to equivalent resources.

\section{Field and laboratory methods}

We conducted one census of each population in fall 1999. Two censuses of each population were conducted per year in 2000 and 2001. At those times, one census was done in the spring, before growth of surrounding vegetation obscured the seedlings, and another was done in the fall, after most mortality of seedlings and canes occurred. In our initial census (1999), all canes were numbered and tagged, and their position within each plot was mapped. In subsequent censuses, we tagged and mapped new canes and recorded the mortality of previously identified canes. 
During a census, canes were classified into one of four stages based on Rubus life-history. These stages were seedling, cane $\mathrm{s}_{\mathrm{s}}$, cane $\mathrm{v}_{\mathrm{v}}$, or reproductive canes (Figure 1). In this study, cane s $_{\mathrm{s}}$ were defined as vegetative canes that had developed from seedlings, while cane ${ }_{\mathrm{v}}$ were vegetative canes that arose from either rhizome sprouting or tip-rooting of reproductive canes. Reproductive canes developed from both cane s $_{\mathrm{s}}$ and cane $\mathrm{v}_{\mathrm{v}}$ and had the potential to produce both fruit and vegetative sprouts $\left(\right.$ cane $\left._{\mathrm{v}}\right)$. In the first census, cane $\mathrm{s}_{\mathrm{s}}$ and cane $\mathrm{v}_{\mathrm{v}}$ were distinguished by their position relative to living or senesced reproductive canes. Our ability to make this distinction was validated by examining root connections in neighboring populations not used in the study. In all subsequent censuses, cane s $_{\mathrm{s}}$ and cane $_{\mathrm{v}}$ were easily distinguished because all seedlings were identified and labeled in a previous census. Over the course of this study, we followed the fate of approximately 600 canes of each species. The nonparametric Kruskal-Wallis (KW) procedure was used to test for differences between the demographic parameters, such as production and survival rates of each life-history stage, for both species at each density.

In spring 2001, floral buds were removed from six entire populations of each species to determine the effects of current reproduction on current growth. Prior to bud removal, average cane length was measured to assess the degree of similarity between these six treatment and six control populations. The control populations were randomly selected from those used in the demographic analyses (three each from low- and high-density). Due to the length and the arching, sprawling growth form of Rubus canes, total cane length could be accurately measured only by harvesting canes. Therefore, we removed three senesced reproductive canes from each of the plots, which would not likely affect the growth or survival of plants remaining in the population. Average cane length per population was not significantly different between control and treatment populations (Wilcoxon Signed Ranks $Z=0.280, P=0.778$ for lowdensity and $Z=0.294, P=0.768$ for high-density $R$. ursinus; and Wilcoxon Signed Ranks $Z=0.643$, $P=0.530$ for low-density and $Z=0.472$, $P=0.647$ for high-density $R$. discolor) and, therefore, the populations were considered similar prior to the floral manipulation. To test for the effect of floral bud removal on growth of cane $_{\mathrm{v}}$, three randomly selected cane $\mathrm{v}_{\mathrm{v}}$ were removed from each of the control and manipulated populations in the fall. Total cane length of each cane $\mathrm{v}_{\mathrm{v}}$ was measured in the field. Then, all leaves from each cane ${ }_{\mathrm{v}}$ were harvested, brought to the lab, and kept in cold storage. Within $\sim 48 \mathrm{~h}$ of harvesting, leaf area of all foliage was determined using a video image recorder and AgVision software (Decagon Devices, Pullman, Washington). Three leaves per cane ${ }_{v}$ were randomly selected, placed in a $65^{\circ} \mathrm{C}$ oven for $48 \mathrm{~h}$, and then weighed to the nearest $0.01 \mathrm{~g}$. Specific leaf area (SLA; leaf area per unit leaf mass) was calculated from these data. The non-parametric wilcoxon signed ranks (WSR) test was used to examine the difference between growth parameters of fruitremoval and control populations because these data did not meet the assumptions for a parametric analysis. Demographic and cane size parameters of control populations were used in a Pearson correla-

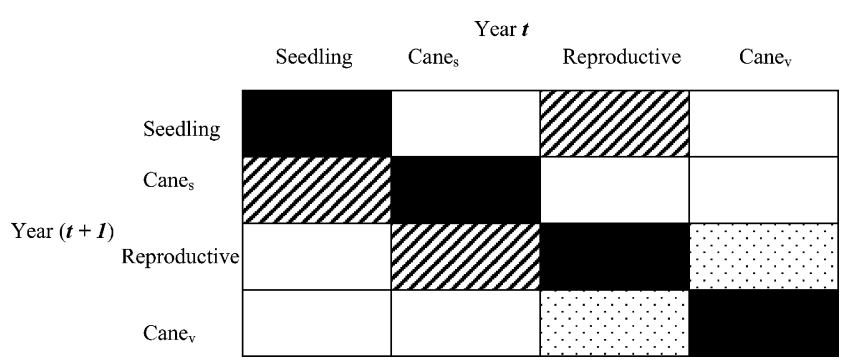

Figure 1. A conceptual transition matrix for $R$. ursinus and $R$. discolor showing possible transitions from one year $(t)$ to the next $(t+1)$. The dark shaded rectangles indicate the transitions $\left(a_{i j}\right)$ associated with continuance in the same stage from one period to the next, stippled rectangles indicate $a_{i j}$ associated with cane production and development arising from vegetative sprouting (cane $\mathrm{v}_{\mathrm{v}}$ ), and hatched rectangles indicate $a_{i j}$ associated with sexual reproduction and growth of canes originating from seeds (cane $)_{\text {) }}$. Transitions without shading were not observed. 
tion matrix to examine life-history trade-offs between years.

\section{Demographic analyses}

The observations made during our field censuses were used to construct stage-based transition matrices with a time interval of one year using the four life-history stages previously described for the Rubus species. Separate transition matrices were constructed for each of the populations over each of the transition intervals to follow the form of projection matrix models

$$
\mathbf{n}(t+1)=A \cdot \mathbf{n}(t)
$$

where $\mathbf{n}(t)$ is a vector of the number of individuals in each of the four stages at time $t, \mathbf{n}(t+1)$ is a vector of the number of individuals in each stage at time $t+1$, and $\boldsymbol{A}$ is a matrix of the transition probabilities $\left(a_{i j}\right)$. The $a_{i j}$ for all transitions except seedling recruitment and cane $\mathrm{v}_{\mathrm{v}}$ production were calculated as the proportion of individuals in stage $i$ at time $t$ that contributed to stage $j$ at time $t+1$ (Figure 1). Occasionally, an individual remained in stage $i$ over a transition interval (Figure 1), although this was rare. Several possible transition probabilities did not occur (e.g., seedlings in one year could not become reproductive canes in the following year) and were, therefore, entered as 0's in the matrix.

Seedling recruitment and cane $\mathrm{v}_{\mathrm{v}}$ production probabilities were calculated as the number of seedlings and cane $\mathrm{v}_{\mathrm{v}}$, respectively, produced in one year relative to the number of reproductive canes existing in the previous year. Our calculation for seedling recruitment was based on the assumption that all seedlings germinated from seeds produced during the previous year and not from the seed bank. This assumption was probably reasonable based on the rapid disappearance of Rubus seeds from the soil due to predation (Maxwell 1990; Kollmann et al. 1998) and the low germination probability of seeds following storage (Amor 1974) or desiccation in the field (S. Lambrecht- McDowell, personal observation).

From each matrix, we calculated the finite rate of population growth, $\lambda$, which is the dominant eigenvalue of $\boldsymbol{A}$. We calculated an average transition matrix for each species in both low- and high-density populations over each transition interval. A value of $\lambda>1$ indicates a positive population growth rate, $\lambda<1$ indicates the population is decreasing in size, and $\lambda=1$ indicates a stable population size. We used an analytical approximation according to Caswell $(2000,2001)$ for the variance $(V)$ of $\lambda$ where

$$
V(\lambda) \approx \sum_{i j} \sum_{k l} \operatorname{Cov}\left(a_{i j} a_{k l}\right) \frac{\partial \lambda}{\partial a_{i j}} \frac{\partial \lambda}{\partial a_{k l}}
$$

for each of these eight average matrices where Cov denotes the covariance between pairs of transition probabilities $\left(a_{i j}\right.$ and $\left.a_{k l}\right)$ and $\partial \lambda / \partial a_{i j}$ is a sensitivity term and denotes the effect of a change in $a_{i j}$ on $\lambda$. We used $t$-tests to determine the significance of the difference between $\lambda$ in low- and high-density populations over a transition interval for each species and between the species and densities for each transition interval.

Given a difference in $\lambda$ between low- and highdensity populations for both species, we used a life table response experiment (LTRE) to determine the contribution $\left(c_{i j}\right)$ of each transition to the effect of population density on $\lambda$ (Levin et al. 1996; Caswell 2000, 2001). The size of each $c_{i j}$ relative to other $c_{i j}$ indicates the relative effect of that transition on the reduction in population growth between low- and high-density populations. In this manner, the LTRE can be used to determine which transitions underlie the population-level effect of density. To calculate the $c_{i j}$ for each species, we first calculated an average transition matrix for all populations at a given density. For $R$. ursinus, we averaged transitions from both transition intervals. However, for $R$. discolor, we only used the transitions from the 2000-2001 interval because we observed no effect of density on $\lambda$ over the 1999-2000 interval for this species. We then calculated a matrix midway between the high- and low-density population matrices for each species where values in the midway matrix were averages of the corresponding values from the mean low-density and mean high-density matrices. Finally, we estimated the effect of density on $\lambda$ by calculating the $c_{i j}$ of each vital rate using the difference between the average matrix elements of high- and low-density populations and using the equation 


$$
c_{i j}=\left(a_{i j}^{h i g h}-a_{i j}^{l o w}\right)\left(\frac{\partial \lambda}{\partial a_{i j}}\right)
$$

where $\left(a_{i j}^{\text {high }}-a_{i j}^{l o w}\right)$ is the difference $\left(d_{i j}\right)$ between the transition values in the low- and high-density matrices and the $\partial \lambda / \partial a_{i j}$ are the sensitivity terms calculated from the matrix midway between the high- and low-density matrices.

\section{Elasticity analysis}

The elasticity of each matrix element $\left(e_{i j}\right)$ is a measure of the proportional sensitivity of $\lambda$ to proportional changes in the $a_{i j}$ (de Kroon et al. 1986; de Kroon et al. 2000; Caswell 2001). Using the same average matrices generated for the LTRE, we calculated the $e_{i j}$ for each $a_{i j}$ as

$$
e_{i j}=\frac{a_{i j}}{\lambda} \frac{\partial \lambda}{\partial a_{i j}}
$$

for each of the four average matrices. The $e_{i j}$ values for a single matrix sum to $100 \%$ and, therefore, it is possible to sum the $e_{i j}$ for transitions associated with the same life-history process (e.g., sexual reproduction or clonal growth) to compare the relative importance of each life-history process to $\lambda$ (Silvertown et al. 1993; van Groenendael et al. 1994; de Kroon et al. 2000). Using the transition matrix in Figure 1, we identified the characteristic life-history processes for the two Rubus species, denoting each with a different type of shading. The $e_{i j}$ of all transitions sharing the same type of shading, and therefore, within the same life-history process, were added.
We used numerical manipulations of seedling and cane $_{\mathrm{v}}$ production to assess the contribution of these transitions to $\lambda$ and to assess the impact of potential control strategies. For each of the four average transition matrices, new $\lambda$ 's were determined by modifying the seedling recruitment transition value by differing proportions (from -90 to $+50 \%$ ), holding all other transition values constant. Similar analyses were repeated for manipulations of the transition value for cane ${ }_{\mathrm{v}}$ production. We also tested whether our assumption that all seedlings germinated from seeds produced during the previous year by adding an additional transition stage (seed) to the model and calculating the change in $\lambda$ and elasticity values for reproduction.

\section{Results}

Trade-offs between growth and reproduction

Flower removal from all reproductive canes within a population only slightly increased cane length production by cane $_{\mathrm{v}}$ for both species. Although the average cane length produced was higher for $R$. ursinus in the flower removal plots relative to the control plots, these differences were not statistically significant at $\alpha=0.05$ (Table 1; low-density WSR $Z=1.244, P=0.095$; high-density WSR $Z=0.524, P=0.300$ ). Average cane length produced by cane $_{\mathrm{v}}$ was more similar between flower removal and control plots of $R$. discolor (Table 1; low-density WSR $Z=0.280, \quad P=0.389 ; \quad$ high-density $\quad$ WSR $Z=0.105, P=0.459)$.

Table 1. Effects of floral bud removal on average cane length produced, leaf area produced per cane, and average specific leaf area

\begin{tabular}{|c|c|c|c|c|c|}
\hline & \multicolumn{3}{|l|}{ R. ursinus } & \multicolumn{2}{|l|}{ R. discolor } \\
\hline & Population density & Control & Floral bud removed & Control & Floral bud removed \\
\hline \multirow[t]{2}{*}{ Cane length produced $(\mathrm{cm})$} & Low & $145.5 \pm 23.2$ & $228.2 \pm 45.7$ & $336.7 \pm 54.1$ & $404.5 \pm 105.7$ \\
\hline & High & $106.9 \pm 16.5$ & $133.9 \pm 16.9$ & $345.1 \pm 41.9$ & $475.4 \pm 135.0$ \\
\hline \multirow[t]{2}{*}{ Leaf area produced $\left(\mathrm{cm}^{2}\right)$} & Low & $319.6 \pm 72.3^{*}$ & $615.0 \pm 176.4^{*}$ & $3492.8 \pm 713.9$ & $3964.6 \pm 939.0$ \\
\hline & High & $156.0 \pm 16.2$ & $201.9 \pm 20.2$ & $2877.0 \pm 623.2$ & $4018.6 \pm 1263.1$ \\
\hline \multirow[t]{2}{*}{ Specific leaf area $\left(\mathrm{cm}^{2} \mathrm{~g}^{-1}\right)$} & Low & $162.1 \pm 7.7^{*}$ & $116.5 \pm 4.7^{*}$ & $88.8 \pm 2.6$ & $64.6 \pm 4.0$ \\
\hline & High & $130.6 \pm 15.6$ & $111.4 \pm 6.4$ & $87.1 \pm 3.4$ & $93.8 \pm 2.2^{*}$ \\
\hline
\end{tabular}
in both low- and high-density populations of $R$. ursinus and $R$. discolor.

Values are the mean $\pm 1 \mathrm{SE}$.

* indicates a significant treatment effect at $\alpha=0.05$ according to the nonparametric Wilcoxon Signed Ranks test. 
In contrast to cane length, leaf growth responded significantly to the flower removal experiment. In low-density populations of $R$. ursinus, flower removal resulted in increased leaf area (Table 1; WSR $Z=1.718, \quad P=0.043$ ) and reduced SLA (WSR $Z=2.667, P=0.004$ ) compared to control plots. There was a similar response in high-density populations of $R$. ursinus, but the differences were not significant at $\alpha=0.05$ (Table 1; leaf area WSR $Z=1.363, P=0.087$; SLA WSR $Z=1.373, \quad P=0.085$ ). Flower removal had no statistically significant impact on leaf area produced per cane for $R$. discolor (Table 1; low-density WSR $Z=0.280, P=0.389$; high-density WSR $Z=0.943, P=0.173$ ), but did significantly increase SLA for high-density populations (WSR $Z=2.694, P=0.004$; low-density WSR $Z=1.234, P=0.125$ ).

Correlations between growth, reproduction, and demographic parameters reveal differences between the species. For $R$. ursinus, leaf area produced per cane $\mathrm{v}_{\mathrm{v}}$ was negatively correlated with both the number of seedlings and the number of cane $_{\mathrm{v}}$ produced per reproductive cane in the previous year (Table $2 ; P=0.028$ and 0.050 , respectively), while there was no such relationship for $R$. discolor (Table 2; $P=0.385$ and 0.695 , respectively). There was a positive correlation between seedling and cane s survival for both species ( $P=0.049$ for $R$. ursinus and $P=0.026$ for
$R$. discolor). For $R$. discolor, there was a negative correlation between cane length and both seedling and cane $)_{\mathrm{s}}$ survival $(P=0.049$ and $P=0.007$, respectively) and between leaf area and cane survival $(P=0.045)$ while there was a positive correlation between cane length production and cane $_{\text {s }}$ survival for $R$. ursinus $(P=0.008)$. Leaf area and cane length were positively correlated for both species $(P=0.003$ for $R$. ursinus and $P<0.0001$ for $R$. discolor).

\section{Demographic patterns}

Populations of the two Rubus species exhibited differences in rates of clonal growth, sexual reproduction, and survival and advancement of individuals to the next stage of development. The noninvasive $R$. ursinus produced more seedlings per $\mathrm{m}^{2}$ in both high- and low-density populations than the invasive $R$. discolor (Table 3; KW $F=22.89, P<0.0001$ ), but the two species produced a similar number of seedlings per reproductive cane (KW $F=4.55, P=0.208$ ). $R$. ursinus also produced more cane $\mathrm{v}_{\mathrm{v}}$ per $\mathrm{m}^{2}$ and per reproductive cane than $R$. discolor (Table $3 ; \mathrm{KW}$ $F=31.32, P<0.0001$ and $F=12.04, P=0.007$, respectively). Although $R$. discolor produced fewer seedlings and cane $\mathrm{v}_{\mathrm{v}}$, its cane $\mathrm{v}_{\mathrm{v}}$ and cane $\mathrm{s}_{\mathrm{s}}$ tended to have higher survival rates than $R$. ursinus $\quad(\mathrm{KW} \quad F=20.01, \quad P<0.001$ and $\mathrm{KW}$

Table 2. Pearson correlation values between demographic parameters of control populations of the noninvasive R. ursinus (upper panel) and the invasive $R$. discolor (lower panel).

\begin{tabular}{|c|c|c|c|c|c|c|c|c|}
\hline & & \multicolumn{7}{|c|}{ Year $t$} \\
\hline & & Canelength & Leaf area & $\begin{array}{l}\text { Cane }_{\mathrm{V}} \\
\text { production }\end{array}$ & $\begin{array}{l}\text { Seedling } \\
\text { production }\end{array}$ & $\begin{array}{l}\text { Seedling } \\
\text { survival }\end{array}$ & $\begin{array}{l}\text { Cane }_{\mathrm{s}} \\
\text { survival }\end{array}$ & $\begin{array}{l}\text { Cane }_{\mathrm{v}} \\
\text { survival }\end{array}$ \\
\hline & Leaf area & $0.781 * *$ & - & & & & & \\
\hline & Cane $_{\mathrm{v}}$ production & -0.183 & $-0.576^{*}$ & - & & & & \\
\hline & Seedling production & -0.317 & $-0.630^{*}$ & 0.362 & - & & & \\
\hline & Seedling survival & -0.006 & -0.384 & 0.263 & 0.212 & - & & \\
\hline & Cane $_{\mathrm{s}}$ survival & $0.723 * *$ & 0.313 & -0.065 & 0.038 & $0.579^{*}$ & - & \\
\hline & Cane $_{\mathrm{v}}$ survival & -0.226 & 0.069 & $-0.796^{* *}$ & -0.052 & -0.073 & -0.145 & - \\
\hline \multicolumn{9}{|l|}{ Year $(t+1)$} \\
\hline & Leaf area & $0.837 * *$ & - & & & & & \\
\hline & Cane $_{\mathrm{v}}$ production & 0.347 & 0.242 & - & & & & \\
\hline & Seedling production & -0.111 & -0.108 & 0.250 & - & & & \\
\hline & Seedling survival & $-0.516^{*}$ & -0.465 & 0.190 & 0.081 & - & & \\
\hline & Cane $_{\mathrm{s}}$ survival & $-0.665 * *$ & $-0.523^{*}$ & 0.270 & 0.288 & $0.573^{*}$ & - & \\
\hline & Cane $_{\mathrm{v}}$ survival & 0.075 & -0.147 & 0.309 & 0.509 & -0.020 & 0.246 & - \\
\hline
\end{tabular}

* Indicates a significant difference at $\alpha=0.05$ and $* *$ indicates a significant difference at $\alpha=0.01$. 
Table 3. Average demographic parameters $\pm 1 \mathrm{SE}$ for the noninvasive $R$. ursinus and the invasive $R$. discolor.

\begin{tabular}{|c|c|c|c|c|}
\hline & \multicolumn{2}{|l|}{ R. ursinus } & \multicolumn{2}{|l|}{ R. discolor } \\
\hline & Low density & High density & Low density & High density \\
\hline Seedlings $\left(\mathrm{m}^{-2}\right)$ & $2.0 \pm 0.5^{\mathrm{a}}$ & $3.6 \pm 0.6^{\mathrm{b}}$ & $0.3 \pm 0.1^{\mathrm{c}}$ & $0.7 \pm 0.2^{\mathrm{c}}$ \\
\hline Cane $_{\mathrm{v}}\left(\mathrm{m}^{-2}\right)$ & $4.9 \pm 0.7^{\mathrm{a}}$ & $14.7 \pm 0.7^{\mathrm{b}}$ & $1.1 \pm 0.2^{\mathrm{c}}$ & $1.5 \pm 0.1^{\mathrm{c}}$ \\
\hline Seedlings per reproductive cane & $1.1 \pm 0.3^{\mathrm{a}}$ & $0.5 \pm 0.1^{\mathrm{a}}$ & $0.3 \pm 0.1^{\mathrm{a}}$ & $0.5 \pm 0.2^{\mathrm{a}}$ \\
\hline Cane $_{\mathrm{v}}$ per reproductive cane & $3.1 \pm 0.6^{\mathrm{a}}$ & $2.4 \pm 0.3^{\mathrm{ab}}$ & $1.4 \pm 0.2^{\mathrm{bc}}$ & $0.9 \pm 0.2^{\mathrm{c}}$ \\
\hline Seedling survival (\%) & $68 \pm 16^{\mathrm{a}}$ & $69 \pm 9^{\mathrm{a}}$ & $79 \pm 9^{\mathrm{a}}$ & $86 \pm 7^{\mathrm{a}}$ \\
\hline Cane $_{\mathrm{s}}$ survival (\%) & $41 \pm 14^{\mathrm{a}}$ & $26 \pm 13^{\mathrm{a}}$ & $58 \pm 14^{\mathrm{a}}$ & $72 \pm 9^{a}$ \\
\hline Cane $_{\mathrm{v}}$ survival (\%) & $70 \pm 7^{\mathrm{a}}$ & $41 \pm 4^{\mathrm{b}}$ & $93 \pm 4^{c}$ & $98 \pm 2^{\mathrm{c}}$ \\
\hline
\end{tabular}

Values of the same parameter sharing letters are not significantly different at $\alpha=0.05$ as determined with the nonparametric Kruskal-Wallis procedure.

$F=6.22, P=0.102$, respectively). Seedling survival was similar between densities for a given species $(\mathrm{KW} F=2.34, P=0.505)$.

\section{Population growth}

Rubus ursinus exhibited positive population growth rates over both transition years in both low- and high-density populations (Figure 2). However, for high-density populations, $\lambda$ was very close to 1 , suggesting that population size in these established populations was fairly constant. The $\lambda$ in low-density populations was higher than that of high-density populations over both transition years $(t=-2.144, P=0.034)$. The range in $\lambda$ for low-density $R$. ursinus populations was $1.22-1.92$ and for high-density populations was $0.72-1.22$.

The average population growth rate of $R$. discolor was positive over both transition years in both low- and high-density populations, except in high-density populations in 2000-2001 (Figure 2). Like $R$. ursinus, $R$. discolor showed an apparently higher $\lambda$ in low-density populations than in high-density populations in 2000-2001 $(t=-6.353, P=0.003)$, but in $1999-2000, \lambda$ was approximately equal between the two population densities $(t=0.705, P=0.262)$. Values of $\lambda$ for $R$. discolor ranged from 0.82 to 1.76 for low-density populations and from 0.70 to 1.41 in highdensity populations.

Population growth rates were similar between the species. $\lambda$ was not significantly different between the species over the 1999-2000 $(t=0.437$, $P=0.402$ for low-density and $t=0.898$, $P=0.251$ for high-density) or 2000-2001 transition intervals $(t=1.428, P=0.223$ for low-density and $t=1.439, P=0.206$ for high-density).
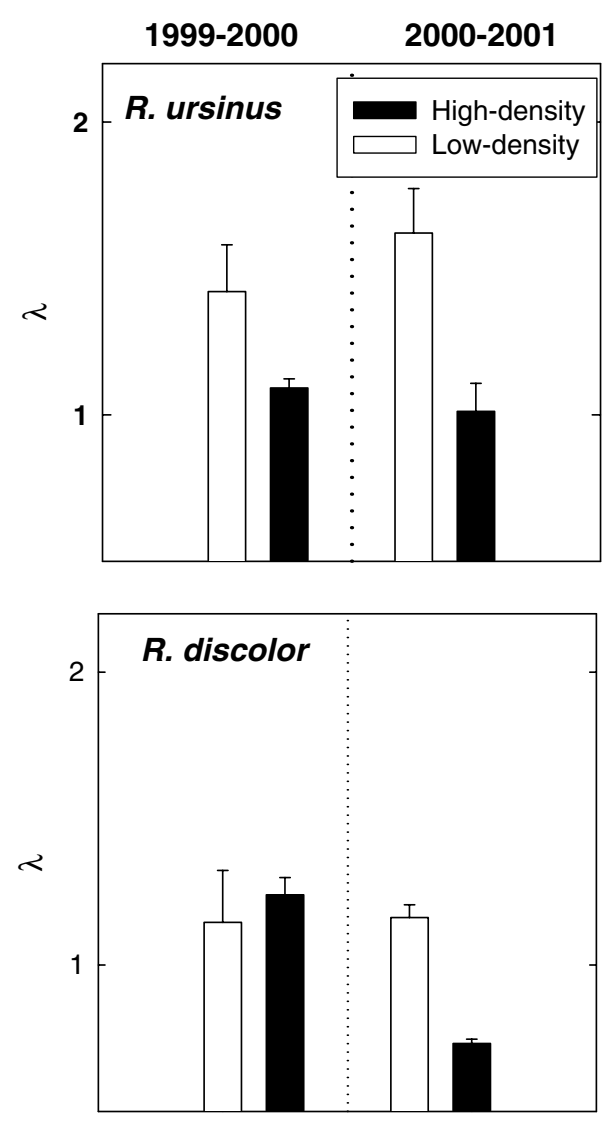

Figure 2. The finite rate of increase $(\lambda)$ for low- (open bars) and high-density (shaded bars) populations of $R$. ursinus and $R$. discolor over each one-year transition interval. Error bars $=1 \mathrm{SE}$ as calculated using an analytical approximation (discussed in the text).

The LTRE revealed that the factors underlying the effects of density on $\lambda$ were different for each of the species. The transition that contributes the 
most to the density-dependent change in $\lambda$ for each species has the largest $c_{i j}$. The $c_{i j}$ for $R$. ursinus reveal that high population density caused reduced cane $\mathrm{v}_{\mathrm{v}}$ survival and, to a lesser degree, reduced cane $\mathrm{v}_{\mathrm{v}}$ production because the $c_{i j}$ for these transitions were largest (Figure 3C). For R. discolor, the reduction in $\lambda$ in high-relative to lowdensity populations was due to reduced cane ${ }_{\mathrm{v}}$ production because this transition had the largest $c_{i j}$ (Figure 3D). For $R$. ursinus, the transition elements that yielded the largest $d_{i j}$ between highand low-density populations did not produce the largest $c_{i j}$ and, therefore, largest effect on $\lambda$ (Figure 3). However, for $R$. discolor, the largest $d_{i j}$ produced the largest $c_{i j}$ (Figure 3 ).

\section{Elasticity analysis}

Comparison of the summed elasticity values for each life-history process indicated that clonal growth affected $\lambda$ relatively more than sexual reproduction for both species in both low and high population densities (Table 4). For R. ursi$n u s$, the contribution of clonal growth and sexual reproduction to $\lambda$ remained relatively constant between low- and high-density populations (Table 5). However, the relative importance of sexual reproduction to $\lambda$ increased between lowand high-density populations of $R$. discolor. The summed elasticity values for sexual reproduction were higher in $R$. discolor than $R$. ursinus, particularly in high-density populations, $(t=0.670$, $P=0.128$ for low-density populations and $t=1.728$ and $P=0.028$ for high-density populations). Similarly, clonal growth contributed slightly more to population growth in $R$. ursinus relative to $R$. discolor $(t=-1.751, P=0.050$ for low-density populations and $t=-1.544$, $P=0.075$ for high-density populations). Adding the seed transition stage to the model reduced $\lambda$ for both species at both densities, but not significantly $(t=1.95, P=0.15$ and $t=0.37, P=0.73$ for $R$. discolor high- and low-density populations, respectively and $t=1.89, P=0.16$ and $t=1.97$, $P=0.15$ for $R$. ursinus high- and low-density populations). For both species, the summed elasticity values for sexual reproduction increased in the high-density populations, but not significantly (5\% increase for $R$. discolor, $t=0.53, P=0.63$ and $1 \%$ increase for $R$. ursinus, $t=2.12$, $P=0.12$ ). In low-density populations of both species, the summed elasticity values for sexual reproduction decreased by a nonsignificant amount (4\% decrease for $R$. discolor, $t=0.96$,

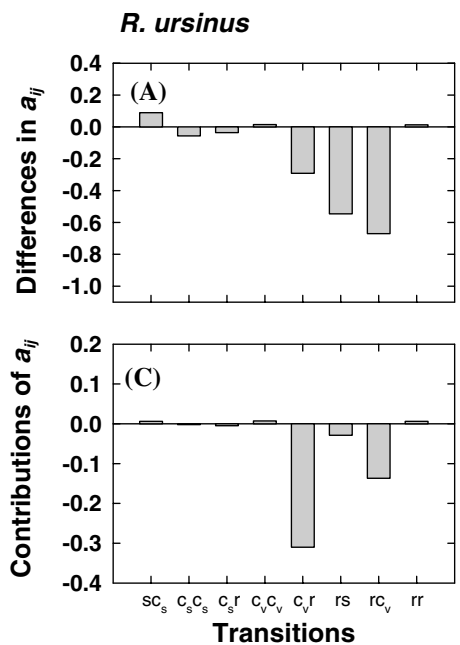

R. discolor

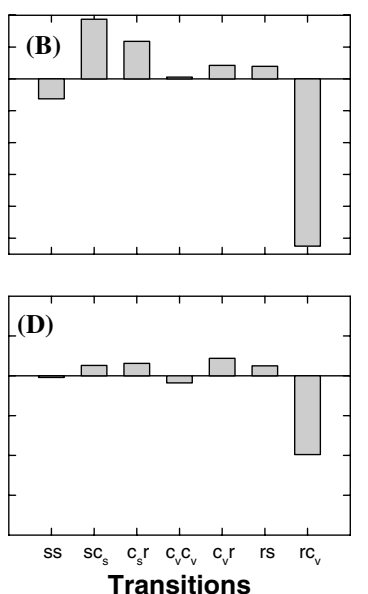

Figure 3. The differences $\left(d_{i j}\right)$ between transition values $\left(a_{i j}\right)$ from the mean low- and mean high-density populations of $R$. ursinus (A) and $R$. discolor (B), and the contribution $\left(c_{i j}\right)$ of each of those differences to the density-dependent change in population growth $(\mathrm{C}$ and $\mathrm{D})$. Abbreviations for transitions from one year to the next are ss (seedling to seedling), $\mathrm{sc}_{\mathrm{s}}$ (seedling to cane $\mathrm{s}_{\mathrm{s}}$ ), $\mathrm{c}_{\mathrm{s}} \mathrm{c}_{\mathrm{s}}\left(\mathrm{cane}_{\mathrm{s}}\right.$ to cane ${ }_{\mathrm{s}}$ ), $\mathrm{c}_{\mathrm{s}} \mathrm{r}$ ( cane $_{\mathrm{s}}$ to reproductive), $\mathrm{c}_{\mathrm{v}} \mathrm{c}_{\mathrm{v}}\left(\mathrm{cane}_{\mathrm{v}}\right.$ to cane $\mathrm{v}_{\mathrm{v}}$ ), $\mathrm{c}_{\mathrm{v}} \mathrm{r}$ ( cane $_{\mathrm{v}}$ to reproductive), rs (seedling recruitment), $\mathrm{rc}_{\mathrm{v}}$ (vegetative cane production), and $\mathrm{rr}$ (reproductive to reproductive). 
Table 4. Average summed elasticity values $\pm 1 \mathrm{SE}$ for sexual reproduction and clonal growth transitions of all low- and high-density populations for each species over both transition years. Transitions included in the sum for sexual reproduction include those depicted with hatched lines in Figure 1, while transitions included in clonal growth include those with dots in Figure 1.

\begin{tabular}{llc}
\hline & \multicolumn{2}{l}{ Mode of reproduction } \\
\cline { 2 - 3 } & Sexual & Clonal \\
\hline R. ursinus & $14 \pm 10$ & $85 \pm 10$ \\
Low density & $13 \pm 6$ & $81 \pm 6$ \\
High density & & \\
$R$. discolor & $20 \pm 8$ & $71 \pm 7$ \\
Low density & $32 \pm 7$ & $68 \pm 8$ \\
High density &
\end{tabular}

$P=0.41$ and $2 \%$ decrease for $R$. ursinus, $t=1.33, P=0.31)$. Therefore, we conclude that our assumption that seeds produced in one year germinated in the following year did not significantly affect the results of our analyses.

For both species, changes in the average cane ${ }_{\mathrm{v}}$ production transition value had a much larger effect on $\lambda$ than proportional changes in the average seedling recruitment value, holding all other transition values constant (Figure 4). For R. ursinus, reducing seedling recruitment by as much as $90 \%$ had virtually no impact on $\lambda$ in both lowand high-density populations while even small changes in cane e $_{\mathrm{v}}$ production had a proportionately larger effect on $\lambda$. In low-density populations of $R$. discolor, the proportional effects of changes in seedling recruitment and cane ${ }_{\mathrm{v}}$ produc- tion on $\lambda$ were similar to the effects observed in R. ursinus (Figure 4). However, in high-density populations of $R$. discolor, changes to the seedling recruitment and to the cane $_{\mathrm{v}}$ production transition value produced more similar effects on $\lambda$.

Figure 5 shows the percent change in $\lambda$ given a $50 \%$ change in either the cane $\mathrm{v}_{\mathrm{v}}$ production or seedling recruitment transition values for each matrix of each species while holding all other transition values constant. For R. ursinus, a $50 \%$ reduction in seedling recruitment yielded a small change in $\lambda$ (always less than $10 \%$ change), while a $50 \%$ change in cane $_{\mathrm{v}}$ production yielded a minimum $15 \%$ change in population growth (Figure 5). For $R$. discolor, although a $50 \%$ change in cane $_{\mathrm{v}}$ production generally had a larger impact on $\lambda$ than a $50 \%$ change in seedling recruitment, the impact of these two transitions on $\lambda$ were more similar to each other than their impacts on $\lambda$ of $R$. ursinus (Figure 5). With a $50 \%$ change in seedling recruitment, $\lambda$ changed by as much as $14 \%$ while a proportional change in cane $_{\mathrm{v}}$ production changed $\lambda$ by as little as $7 \%$.

\section{Discussion}

\section{Trade-offs between growth and reproduction}

The demographic trade-offs between current sexual reproduction and growth of cane $_{\mathrm{v}}$ within a clone are more evident in the noninvasive

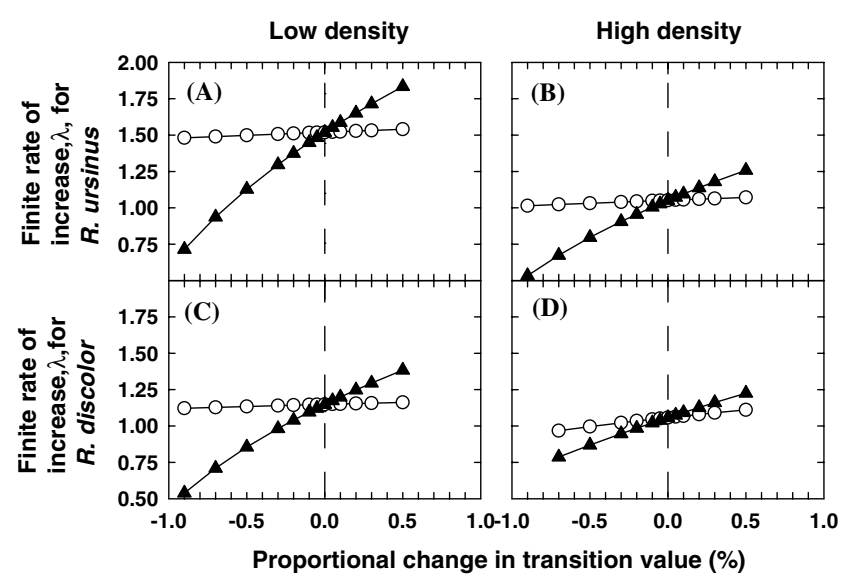

Figure 4. The finite rate of increase $(\lambda)$ for a proportional change in the average transition value of seedling recruitment (circles) and cane $\mathrm{v}_{\mathrm{v}}$ production (triangles) for R. ursinus in low- (A) and high-density (B) populations and for R. discolor in low- (C) and high- (D) density populations. 


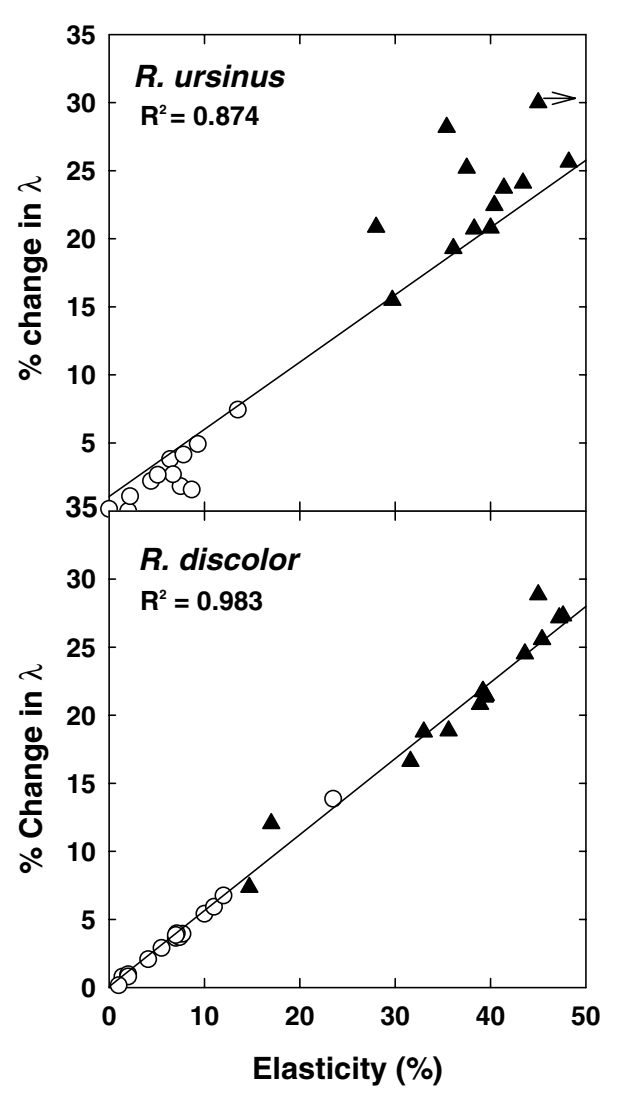

Figure 5. The percent change in the finite rate of increase $(\lambda)$ for a $50 \%$ proportional change in seedling recruitment (circles) and cane $\mathrm{v}_{\mathrm{v}}$ production (triangles) versus the elasticity value $\left(e_{i j}\right)$ for each fecundity and cane $\mathrm{v}_{\mathrm{v}}$ transition for each matrix of $R$. ursinus and $R$. discolor. For $R$. ursinus, $\lambda=1.06+0.49 e_{i j} \quad(P<0.0001)$ and for $R$. discolor, $\lambda=0.06+0.56 e_{i j}(P<0.0001)$.

$R$. ursinus than in the invasive $R$. discolor. Tradeoffs between current growth and reproduction have been observed in studies with natural and manipulated levels of reproduction for noninvasive species (Fox and Stevens 1991; Newell 1991; Ashman 1992; Nicotra 1999). However, little is known about these trade-offs in an invasive plant species. The apparent trade-offs in $R$. ursinus were driven by the physiological costs associated with reproduction, leading to relatively higher reproductive effort. A previous study of these same two species demonstrated that sexual reproduction caused decreased foliar water status and photosynthetic capacity in $R$. ursinus, leading to a reduction in annual carbon gain (McDowell and Turner 2002). These effects of reproduction on carbon gain, however, were not apparent in $R$. discolor, thus explaining the apparent lack of growth response to floral bud removal observed in this study.

In addition to the trade-off between current growth and reproduction, plants may also exhibit a negative relationship between current reproduction and future growth and reproduction. If current and future reproduction draw on the same pool of resources, then current reproduction may deplete available resources for future growth, flower, and fruit development (Stearns 1992). Furthermore, the negative effects of reproduction on current plant size may decrease a plant's capacity to acquire resources in the future (Bloom et al. 1985) or limit the number of meristems that may develop into inflorescences (Geber 1990). The negative correlation between leaf area production per cane $\mathrm{v}_{\mathrm{v}}$ of $R$. ursinus in one year and cane $\mathrm{v}_{\mathrm{v}}$ production in the following year suggests trade-offs may exist between generations in the noninvasive Rubus because these two parameters, as components of clonally integrated canes, draw on the same pool of resources. Although there is a negative correlation between leaf area production in one year and seedling production in the following, this correlation may be spurious. In order for seedling production to have an effect on resource allocation to leaf area production of cane $e_{v}$, the seeds from which those seedlings germinated must have been produced by reproductive canes clonally connected to the affected cane $_{\mathrm{v}}$. In this study, it was not possible to determine the seed source of the germinated seedlings.

The demographic trade-offs between growth and reproduction within and between generations were not apparent in the invasive $R$. discolor. It is possible that such life-history trade-offs are not apparent when resources are not limiting, when different life-history functions are dependent upon separate resource pools, or when current allocation does not affect the capacity of a plant to capture resources in the future (Geber 1990; Stearns 1992). The two Rubus species examined in this study grow in the same open sites and, therefore, have potential access to equivalent resources. However, $R$. discolor is able to achieve higher photosynthetic rates per unit resource investment of carbon, water, and nitrogen than 
R. ursinus (McDowell 2002). Therefore, resource availability may be more limiting to carbon gain in $R$. ursinus than in $R$. discolor. Furthermore, the lack of effect of reproduction on carbon gain in $R$. discolor highlights a possible mechanism underlying the apparent lack of trade-offs for this species (McDowell and Turner 2002).

\section{Demographic patterns}

Rates of production and survival of canes within populations were different for the species. The higher rate of seedling and cane $\mathrm{v}_{\mathrm{v}}$ production by $R$. ursinus on a ground area basis is due, at least in part, to the smaller size of $R$. ursinus canes; more small canes can grow in a given area than large canes. However, R. ursinus also produced more cane $_{\mathrm{v}}$ per reproductive cane, a value that was standardized for plant size. Although $R$. discolor produced fewer cane $_{\mathrm{v}}$, they had a higher survival rate than the cane $\mathrm{v}_{\mathrm{v}}$ of $R$. ursinus. In fact, the noninvasive $R$. ursinus displayed a demographic trade-off between cane $_{\mathrm{v}}$ production and survival, as evidenced by the negative correlation between these two parameters. For $R$. discolor, there was a positive, although not significant, relationship between cane ${ }_{\mathrm{v}}$ production and survival, suggesting there was no demographic trade-off between these two parameters.

\section{Population growth and invasiveness}

As plant populations become more dense, they eventually reach the site carrying capacity and are subject to density-dependent limits on recruitment of new individuals. In short-lived species such as Rubus, recruitment may be expected to plateau so that each year, the population merely replaces senescing canes. Clonal plants commonly show constant rates of mortality and recruitment following population establishment so that cane $\mathrm{v}_{\mathrm{v}}$ numbers remain relatively constant (Cook 1985; Hartnett and Bazzaz 1985; Meyer and Schmid 1999). For both Rubus species in this study, $\lambda$ of the high-density populations was approximately equal to 1 , suggesting that the populations had, on average, reached a plateau in population growth. Furthermore, $\lambda$ was higher in low- than in high-density populations, with the exception of $R$. discolor over the 1999-2000 transition. This pattern of population growth is similar to that of other clonal plant species (Barkham 1980; Cook 1985; Briske and Butler 1989) as well as that of the invasive, but non-clonal, Cytisus scoparius (Parker 2000), in response to increasing population density. The LTRE showed that for $R$. ursinus, the effect of density on $\lambda$ was due to a reduction in cane ${ }_{\mathrm{v}}$ survival with increasing population density, while in $R$. discolor, the difference was due to a reduction in cane $_{\mathrm{v}}$ production. Reduced cane $\mathrm{v}_{\mathrm{v}}$ production, rather than increased mortality, is a more commonly observed response to increased population density in other clonal plant species (Cook 1985; Briske and Butler 1989), perhaps because cane ${ }_{\mathrm{v}}$ mortality generates a resource cost for the entire clone. The mortality of cane $_{\mathrm{v}}$ in $R$. ursinus was particularly pronounced over the 2000-2001 transition interval, along with mortality of other life-history stages, and may have arisen due to the colder than normal conditions during the winter and much drier than normal spring. $R$. discolor, which is more tolerant of seasonal and diurnal drought than $R$. ursinus (McDowell 2002; McDowell and Turner 2002), may have been less adversely affected by the climate over that transition interval.

The elasticity analysis revealed that life stage transitions relating to cane $_{\mathrm{v}}$ production and survival were relatively more important to population growth of both species than transitions relating to sexual reproduction. A reliance on predominantly clonal spread over sexual reproduction has been observed in other species of $R u$ bus (Abrahamson 1975; Maxwell et al. 1993; Baret et al. 2003), as well as other plants that reproduce both sexually and clonally (Cook 1985). There are several advantages associated with the reliance on clonal growth for population expansion. Although cane $_{\mathrm{v}}$ production may require an initial investment of more resources than sexual reproduction, cane $_{\mathrm{v}}$ eventually contribute positively to the resource balance of the clone (Cook 1985), increase the capacity of the clone to recover from stresses such as defoliation (Price et al. 1992), and increase the potential for the clone to access unevenly distributed resources, such as light and water (Stuefer et al. 1996). Furthermore, production of cane $_{\mathrm{v}}$ enables a clone to rapidly capture and dominate an area, competitively excluding other species (Pitelka and 
Ashmun 1985). Finally, life history processes with fewer transitions contribute relatively more to population growth than those with more transitions (de Kroon et al. 2000). Therefore, development of cane $\mathrm{v}_{\mathrm{v}}$ contributes more to population growth of Rubus because it takes two years for a reproductive cane to develop from clonal origins, while it takes three years for a reproductive cane to develop from seed.

Population growth rates within existing populations were similar among the species across both densities and transition intervals. Therefore, invasiveness of $R$. discolor may be due to a greater capacity for dispersal and establishment of new populations than $R$. ursinus, where invasiveness is defined as the ability to rapidly colonize sites, reproduce, and spread to new sites outside of the species' previous range. We did not explicitly measure dispersal or establishment rates of new populations for these species, but we did observe a relative increase of importance of sexual reproduction with population density for $R$. discolor. This increase was due to seedlings germinating in locations within the high-density plots that had not been previously colonized by clonal spread. The minimal physiological costs associated with sexual reproduction for $R$. discolor (McDowell and Turner 2002) mean that the importance of sexual reproduction in populations may increase without incurring negative effects on the current population. $R$. ursinus relied almost entirely on clonal spread for population growth and, therefore, had limited potential for dispersal.

\section{Control of R. discolor}

The elasticity analysis for $R$. discolor may be useful in determining methods for controlling this species. In order to control invasive plant species, population growth needs to be lowered to below $\lambda=1$, so that population size will decrease. One biological control strategy suggested for several other invasive plant species is to utilize predators or pathogens to reduce flower or seed development (Shea and Kelly 1998; McEvoy and Coombs 1999; Parker 2000). Seed predation could reduce population growth of established populations of $R$. discolor by limiting dispersal, but only if seedling recruitment is reduced by at least $70 \%$. The most effective strategy for controlling population growth for existing populations of $R$. discolor would be to reduce cane v $_{\mathrm{v}}$ production. The numerical simulations in this study showed that reducing cane $\mathrm{v}_{\mathrm{v}}$ production by as little as $30 \%$ could reduce population growth adequately to bring about eventual extinction of existing populations. Control methods that involve mowing canes or applying herbicide to foliage have proven relatively ineffective at controlling this species (reviewed in Hoshovsky 2001), probably because such methods have failed to adequately affect allocation to the belowground portions of the plant. The most effective controls for this invasive Rubus include the introduction of animals that graze canes to the roots from which cane $\mathrm{v}_{\mathrm{v}}$ sprout (Amor 1974; Daar 1983) or the use of herbicides applied to cut or burned stems following fruit set (Hoshovsky 2001). The effectiveness of this latter approach is likely due to the translocation of nutrients and, therefore, herbicides from reproductive canes to the roots prior to senescence. Such management tactics, in addition to reducing seedling recruitment to limit dispersal and establishment of new populations, could be effective in controlling established populations of this invasive species in the PNW.

\section{Acknowledgements}

The authors would like to acknowledge the McDonald-Dunn Research Forest and CFIRP for use of field sites. We thank B. Endress, R. Meilan, P. Muir, and three anonymous reviewers for their comments on this manuscript. This research was funded by Sigma Xi Grant-in-Aid of Research, Northwest Science Research Fellowship, and the Graduate Women in Science Vessa Notchev Fellowship to SCLM.

\section{References}

Abrahamson WG (1975) Reproductive strategies in dewberry. Ecology 56: 721-726

Amor RL (1974) Ecology and control of blackberry (Rubus fruticosus L. agg.) II. Reproduction. Weed Research 14: 231-238 
Ashman TL (1992) Indirect costs of seed production within and between seasons in a gynodioecious species. Oecologia 92: 266-272

Baker HG (1965) Characteristics and modes of origin in weeds. In: Baker HG and Stebbins GL (eds) The Genetics of Colonizing Species, pp 147-168. Academic Press, New York

Baret S, Nicolini E, LeBourgeois T and Strasberg D (2003) Development patterns of the invasive bramble (Rubus alceifolius Poiret, Rosaceae) in Reunion Island: an architectural and morphometric analysis. Annals of Botany 91: 39-48

Barkham JP (1980) Population dynamics of the wild daffodil (Narcissus pseudonarcissus). I. Clonal growth, seed reproduction, mortality and the effects of density. Journal of Ecology 68: 607-633

Bazzaz FA (1986) Life history of colonizing plants: some demographic, genetic, and physiological features. In: Mooney HA and Drake JA (eds) Ecology of Biological Invasions of North America and Hawaii, pp 96-110. SpringerVerlag, New York

Bloom AJ, Chapin FS III and Mooney HA (1985) Resource limitation in plants - an economic approach. Annual Review of Ecology and Systematics 16: 363-392

Briske DD and Butler JL (1989) Density-dependent regulation of ramet populations within the bunchgrass Schizachyrium scoparium: interclonal versus intraclonal interference. Journal of Ecology 77: 963-974

Caswell H (2000) Prospective and retrospective perturbation analyses and their roles in conservation biology. Ecology 8: 619-627

Caswell H (2001) Matrix Population Models: Construction, Analysis and Interpretation. Sinauer, Sunderland, Massachusetts

Charron D and Gagnon D (1991) The demography of northern populations of Panax quinquefolium (American ginseng). Journal of Ecology 79: 431-445

Cook RE (1985) Growth and development in clonal plant populations. In: Jackson JBC Buss LW and Cook RE (eds) Population Biology and Evolution of Clonal Organisms, pp 259-296. Yale University Press, New Haven, Connecticut

Daar S (1983) Using goats for brush control. The IPM Practitioner 5: 4-6

Daehler CC (1998) The taxonomic distribution of invasive angiosperm plants: ecological insights and comparison to agricultural weeds. Biological Conservation 84: 167-180

de Kroon H, Plaisier A, van Groenendael J and Caswell $\mathrm{H}$ (1986) Elasticity: the relative contribution of demographic parameters to populations growth rate. Ecology 67: 14271431

de Kroon H, van Groenendael J and Ehrlén J (2000) Elasticites: a review of methods and model limitations. Ecology 81: $607-618$

Fox JF and Stevens GC (1991) Costs of reproduction in a willow: experimental responses vs. natural variation. Ecology 72: 1013-1023

Geber MA (1990) The cost of mersitem limitation in Polygonum arenastrum: negative genetic correlations between fecundity and growth. Evolution 44: 799-819
Hartnett DC and Bazzaz FA (1985) The genet and ramet population dynamics of Solidago canadensis in an abandoned field. Journal of Ecology 73: 407-413

Heslop-Harrison Y (1959) Natural and induced rooting of the stem apex in Rubus. Annals of Botany 23: 307-318

Hoshovsky M (2001) Element Stewardship Abstract for Rubus discolor. The Nature Conservancy, Arlington, Virginia

Kaye TN, Pendergrass KL, Finley $\mathrm{K}$ and Kauffman JB (2001) The effect of fire on the population viability of an endangered prairie plant. Ecological Applications 11: 1366-1380

Keddy PA, Twolan-Strutt L and Wisheu IC (1994) Competitive effect and response ranking in 20 wetland plants: are they consistent across three environments? Journal of Ecology 82: 635-643

Kent DH (1988) Rubus procerus 'Himalayan Giant.' The Kew Magazine 5: 32-35

Kollmann J, Coomes DA and White SM (1998) Consistencies in post-dispersal seed predation of temperate fleshy-fruited species among season, years, and sites. Functional Ecology 12: 683-690

Levin L, Caswell H, Bridges T, DiBacco C, Cabrera D and Plaia G (1996) Demographic responses of estuarine polychaetes to pollutants: Life table response experiments. Ecological Applications 6: 1295-1313

Maschinski J, Frye R and Rutman S (1997) Demography and population viability of an endangered plant species before and after protection from trampling. Conservation Biology 11: 990-999

Maxwell BD (1990) The population dynamics and growth of salmonberry (Rubus spectablilis) and thimbleberry (Rubus parviflorus). PhD Dissertation. Department of Forest Science, Oregon State University, Corvallis, Oregon

Maxwell BD, Wilson MV and Radosevich SR (1988) Population modeling approach for evaluating leafy spurge (Euphorbia esula) development and control. Weed Technology 2: 132-138

Maxwell BD, Zasada JC and Radosevich SR (1993) Simulation of salmonberry and thimbleberry population establishment and growth. Canadian Journal of Forest Research 23: 2194-2203

McDowell SCL (2002) Photosynthetic characteristics of invasive and noninvasive species of Rubus (Rosaceae). American Journal of Botany 89: 1431-1438

McDowell SCL and Turner DP (2002) Reproductive effort in invasive and noninvasive Rubus. Oecologia 133: 102-111

McEvoy PB and Coombs EM (1999) Biological control of plant invaders: regional patterns, field experiments, and structured population models. Ecological Applications 9: $387-401$

Meyer AH and Schmid (1999) Experimental demography of rhizome populations of establishing clones of Solidago altissima. Journal of Ecology 87: 42-54

Newell EA (1991) Direct and delayed costs of reproduction in Aesculus californica. Journal of Ecology 79: 365-378

Nicotra AB (1999) Reproductive allocation and the long-term costs of reproduction in Siparuna grandiflora, a dioecious neo-tropical shrub. Journal of Ecology 87: 138-149 
Parker I.M (2000) Invasion dynamics of Cytisus scoparius: a matrix model approach. Ecological Applications 10: 726-743

Pitelka LF and Ashmun JW (1985) Physiology and integration of ramets in clonal plants. In: Jackson JBC, Buss LW and Cook RE (eds) Population Biology and Evolution of Clonal Organisms, pp 399-435. Yale University Press, New Haven, Connecticut

Price EA, Marshall C and Hutchings MJ (1992) Studies of growth in the clonal herb Glechoma hederacea. I. Patterns of physiological integration. Journal of Ecology 80: 25-38

Reichard SH and Hamilton CW (1997) Predicting invasions of woody plants introduced into North America. Conservation Biology 11: 193-203

Sakai AK, Allendorf FW, Holt JS, Lodge DM, Molofsky J, Baughman S, Cabin RJ, Cohen JE, Ellstrand NC, McCauley DE, O'Neil P, Parker IM, Thompson JN and Weller SG (2001) The population biology of invasive spe- cies. Annual Review of Ecology and Systematics 32: 305332

Shea K and Kelly D (1998) Estimating biocontrol agent impact with matrix models: Carduus nutans in New Zealand. Ecological Applications 8: 824-832

Silvertown J, Franco M, Pisanty I and Mendoza A (1993) Comparative plant demography-relative importance of lifecycle components to the finite rate of increase in woody and herbaceous perennials. Journal of Ecology 81: 465-476

Stearns SC (1992) The Evolution of Life Histories. Oxford University Press, Oxford

Stuefer JF, de Kroon H and During J (1996) Exploitation of environmental heterogeneity by spatial division of labour in a clonal plant. Functional Ecology 10: 328-334

van Groenendael J, de Kroon H, Kalisz S and Tuljapurkar S (1994) Loop analysis: evaluating life history pathways in population projection matrices. Ecology 75: 2410-2415 